\title{
Coelomocytes: Biology and Possible Immune Functions in Invertebrates with Special Remarks on Nematodes
}

\author{
Qudsia Tahseen \\ Nematode Research Laboratory, Department of Zoology, Aligarh Muslim University, Aligarh 202002, India \\ Correspondence should be addressed to Qudsia Tahseen, qtahseen@yahoo.com
}

Received 4 June 2008; Revised 22 September 2008; Accepted 6 November 2008

Recommended by Gregory Demas

\begin{abstract}
All metazoans are exposed to a wide range of microbes and have evolved complex immune defenses used to repel infectious agents. Coelomocytes play a key role in the defense reactions of most invertebrates. They are involved in important immune functions, such as phagocytosis, encapsulation, graft rejection, and inflammation, as well as the synthesis and secretion of several humoral factors especially in annelids and echinoderms. Coelomocytes in nematodes are variable in shapes from round, ovoid, cuboidal, and spindle-shaped to stellate or branched cells that are found usually at fixed positions in the pseudocoelom. Their number usually varies from 2 to 6 . The model nematode, C. elegans lacks an adaptive immune system and the coelomocytes are capable of endocytosis, but their involvement in phagocytosis of bacteria seems unlikely. The aim of this review is to evaluate current knowledge on coelomocytes of invertebrates with special reference to nematodes. The morphology and structure of these coelomocytes are discussed along with their origin. Their relative positions and diversity in different nematode groups have also been discussed and illustrated.
\end{abstract}

Copyright (C) 2009 Qudsia Tahseen. This is an open access article distributed under the Creative Commons Attribution License, which permits unrestricted use, distribution, and reproduction in any medium, provided the original work is properly cited.

\section{Introduction}

Invertebrate organisms have developed a variety of defense reactions to fight invading foreign agents. The invertebrates possess nonadaptive, innate, nonclonal, nonanticipatory immune responses contrary to vertebrate responses which are induced, adaptive, acquired, clonal, and anticipatory [1]. Invertebrates do not possess the immunoglobulins found in higher animals, although proteins containing immunoglobulin-like domains have been identified [2]. The common defense mechanisms used by most invertebrates to protect themselves against infectious agents are the synthesis and secretion of antibacterial and antifungal proteins, agglutination and nodule formation, encapsulation of foreign objects, and phagocytosis. During defense reactions, invariably the foreign organisms are found to be encapsulated and melanized and enzymes (i.e., phenol oxidase) play a vital role in defense reactions. Among the lower forms, protists are the prototypes of macrophages; sponges distinguish between self and nonself; cnidarians have the phagocytes and cnidoblasts while some species are also provided with C3-like molecules.

Careful study of the phylogeny of the immune system has revealed the evolution of three important components, namely, the macrophage, lymphatic, and hematopoietic systems [3]. The most ancient is the macrophage system (largely found in invertebrates) that arises in the coelomic cavity as mesenchymal amoeboid cells or coelomocytes for recognition of self from nonself and for ingestion of foreign particles. The lymphatic system in higher animals develops from the endoderm of pharyngeal pouches, while the hematopoietic system originates from the splanchnic mesoderm of the yolk sac as hematogenic tissue, containing hemangioblasts.

Coelomocytes n. pl. (Gr. koilos, hollow; kytos, container) are cells that tend to be obscure but are apparently omnipresent in most coelomates. The nonmuscle macrophage-like cells inhabit the body cavity or the coelomic spaces of many invertebrates. In annelids, the cells found in coelom are categorized as coelomocytes, chloragogen cells (eleocytes), and haemocytes [4]. The molluscs such as gastropods have haemocytes in the body cavity [5]. The coelomic cells are also referred to as haemocytes in most arthropods [6]. In echinoderms, the coelomocytes occupy perivisceral coelomic cavities, the water-vascular system, and the haemal system besides the connective tissue and tissues of various organs $[7,8]$. Nematodes possess mesenchymatous 
coelomocytes in their pseudocoelom, adjacent to the gonads or other internal organs in the anterior or posterior body regions. These cells were assumed to be phagocytic to purify the body fluid and, therefore, attributed different functions by different workers and assigned different names such as amoebocytes, elaeocytes, athrocytes, and phagocytes. Due to their small size and relatively lesser number, these cells were largely ignored in nematodes particularly in the early developmental stages [9].

The ability of nematodes to osmoregulate varies considerably; free-living forms which are exposed to wide variations in osmotic pressure are extremely efficient osmoregulators; the parasitic forms, on the other hand, may have relatively limited osmoregulatory capacity. In animal parasitic nematodes, the stellate pseudocoelomocytes have been suggested to maintain the pseudocoelomic fluid, either as phagocytic cells removing bacteria and other pathogens or collecting certain xenobiotics molecules and effectively removing them from the coelomic fluid or as further playing a role in haem metabolism [10-12].

Although the function of nematode pseudocoelomocytes (=coelomocytes) was not precisely known for a long time, yet the coelomocytes were frequently studied. Coelomocytes were first observed and reported in the form of four stellate cells in Parascaris equorum in anterior third region of the body by Bojanus [13]. Later Bugnion [14] and von Linstow [15] regarded them as blood corpuscles of nematodes. Jägerskiöld [16-18], Nassonov [19, 20], and Shipley [21] also observed and referred to such cells in their studies. Rauther [22] described them to be fixed in position and attached to the body wall by fine processes. They were also reported to be present in oxyurids and ascarids by Martini $[23,24]$ and Höeppli [25]. Stefanski [26] found them existing between the base of pharynx and anterior end of ovary or testis in Rhabditella axei while B.-G. Chitwood and M. B. Chitwood [27] reported two binucleated " $\mathrm{X}$ " bodies in Cephalobellus papilliger. B. G. Chitwood and M. B. Chitwood [28], Weinstein [11,29], Douvres et al. [30], Peregrine [12], Boghen and Davey [31], Ishikawa [32], Poinar and Jansson [33], A. F. Bird and J. Bird [34] described coelomocytes in free-living and animal parasitic nematodes.

\section{Evaluation of Morphology of Coelomocytes}

2.1. Shape. The pseudocoelomic body cavity of the rotifer Asplanchna spp. contains free cells (coelomocytes) that form a highly dynamic, three-dimensional polygonal network of filopodia. Despite their morphological heterogeneity, coelomocytes have not been categorized for systematic comparison of nematodes. Members of the Secernentea usually possess prominent, unbranched or branched coelomocytes [27] where large vertebrate parasites like Ascaris and Strongylus have branched coelomocytes [27]. The greater size of the coelomocytes and their numerous branches bearing many cytoplasmic swellings increase cellular surface area and metabolic efficiency in Ascaris. The groups, Torquentia and Penetrantia, appear to have ovoid and usually unbranched pseudocoelomocytes. In general, pseudocoelomocytes of
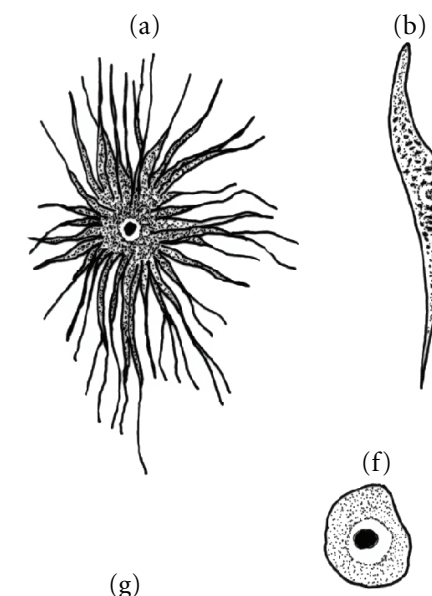

(b)
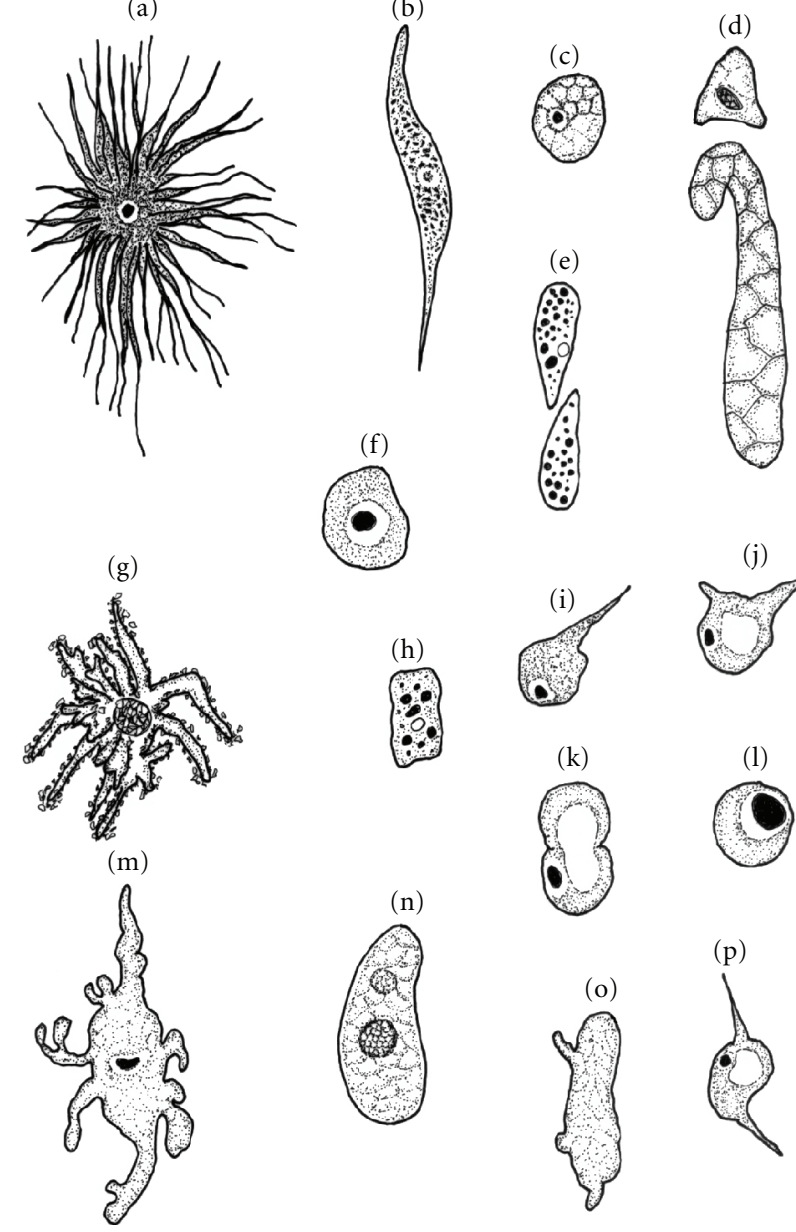

(n)
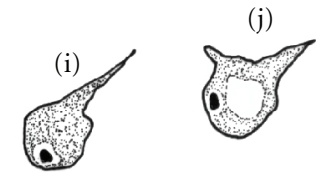

$(\mathrm{k})$

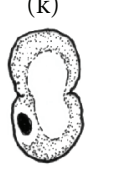

(1)

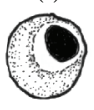

(p)

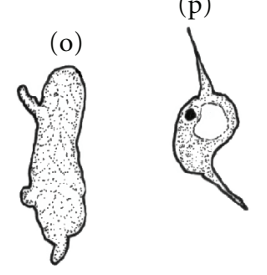

FIGURE 1: Coelomocytes in free-living and parasitic nematodes. (a) Stellate cell in Strongylus sp. (b) Spindle-shaped coelomocytes in Blatticola sp. (c), (f), (l) Round coelomocytes in rhabditids. (d) Coelomocyte close to developing genital primordium. (e) Paired coelomocytes in Panagrolaimus sp. (g) Branched cell in Ascaris sp. (h) Cuboidal coelomocyte in Monhystera sp. (i), (j) Angular coelomocytes in rhabditids. (k) Bilobed coelomocyte in Curviditis sp. (m), (o) Coelomocyte in strongylid. (n) Reniform coelomocyte in Plectus sp. (p) Bipolar coelomocyte in Oscheius sp.

nematodes tend to be variable in shapes from rounded, ovoid, cuboidal, spindle-shaped to stellate or branched cells (Figures 1 and 2) with relatively fixed positions [34]. In Caenorhabditis elegans, they are small rounded cells with small yet discernible nuclei (Figures 3(a), 3(b), and $3(\mathrm{~g}))$. Some coelomocytes may have a reticulate network (Figure 3(1)) while others may have several small vacuoles (Figures 3(a), 3(d), and 3(h)) contained within. In ascarids, there are two or four large branched cells with a central nucleated body and numerous radiating branches. The amoeboid extensions of the coelomocytes of Ascaris suum and Parascaris equorum show terminal swellings [10]. In free-living rhabditid nematodes, pseudocoelomocytes are usually small spherical (Figures 3(a)-3(g), and 3(p)) or ovoid cells (Figures 3(i) and 3(o)) with rather obscure nuclei. However, in an insect-associate rhabditid, Distolabrellus veechi the coelomocytes tend to be larger and prominent 


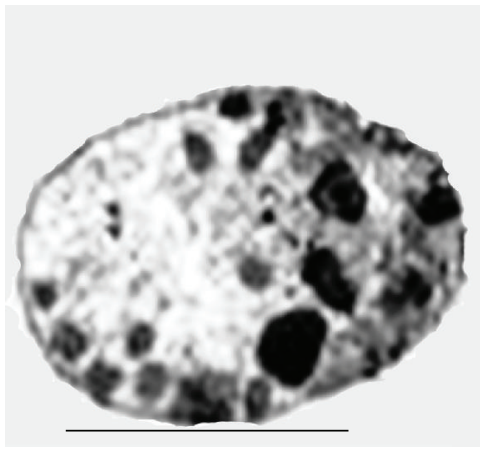

(a)

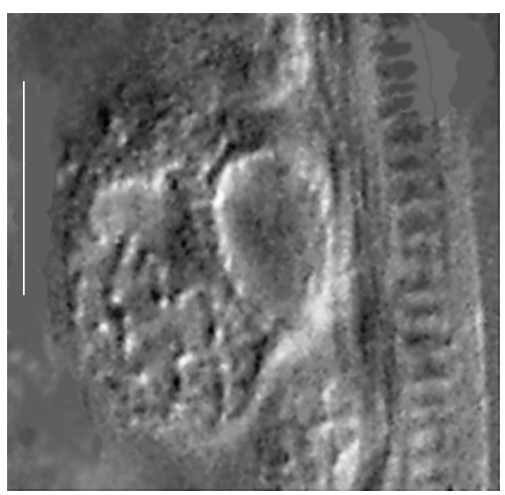

(d)

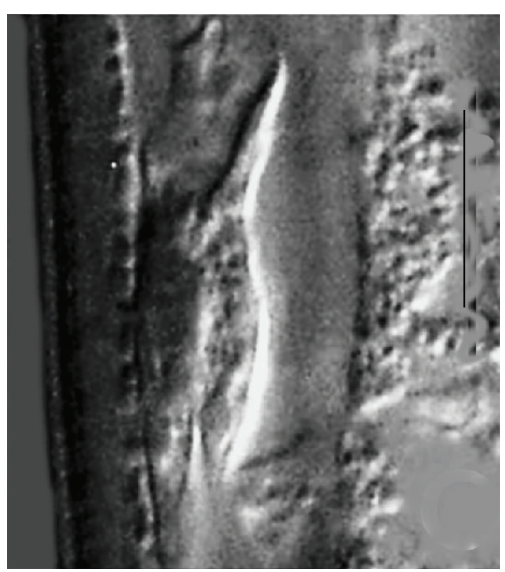

(g)

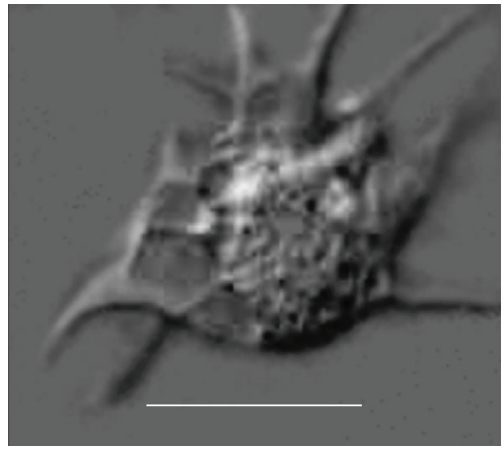

(b)

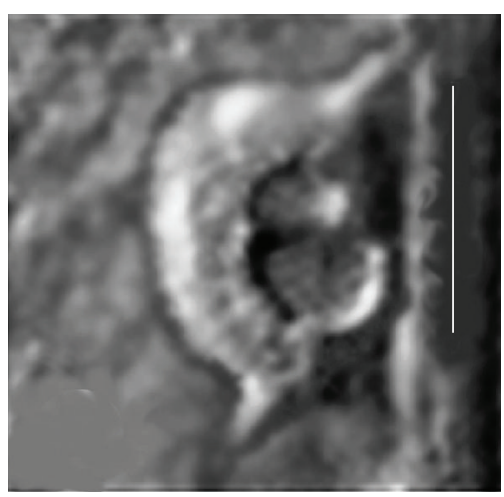

(e)

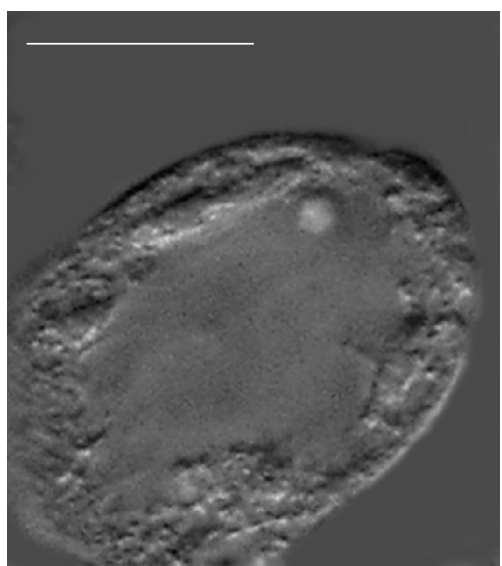

(h)

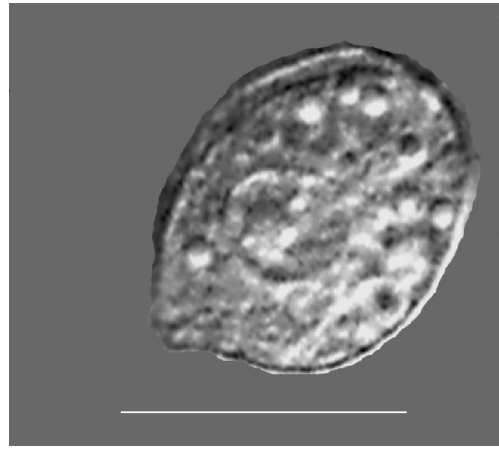

(c)

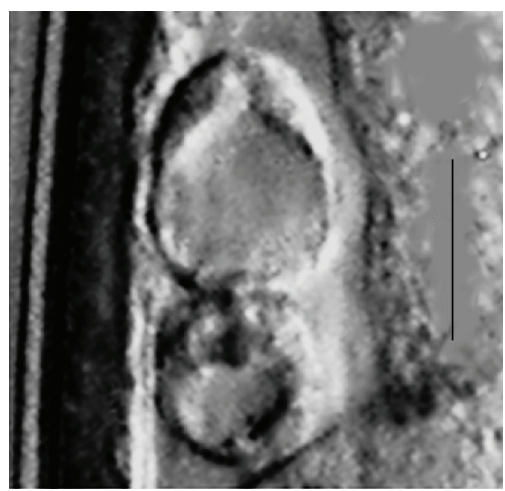

(f)

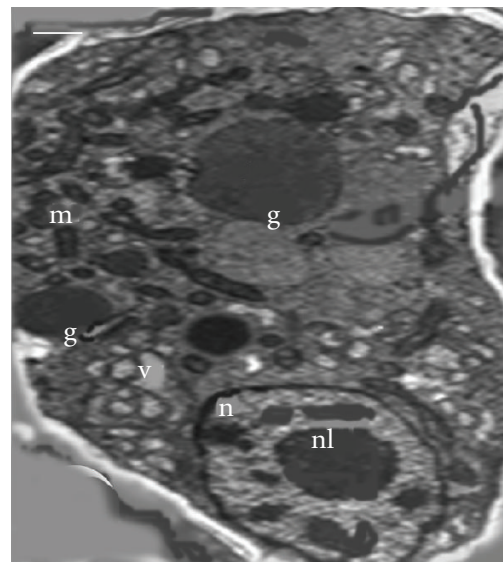

(i)

Figure 2: (a)-(h) Light micrograph (DIC) of coelomocytes. (a) Round granular type. (b) Reticulate type. (c) Ovoid type with distinct nucleus. (d) Round vacuolated type. (e), (g) Bipolar type. (f) Bilobed type. (h) Ovoid type. (i) Transmission electron micrograph of coelomocyte: $\mathrm{g}=$ granule; $\mathrm{n}=$ nucleus; $\mathrm{nl}=$ nucleolus; $\mathrm{m}=$ mitochondria; $\mathrm{v}=$ vesicle (scale bar $\mathrm{A}-\mathrm{H}=5 \mu \mathrm{m} ; \mathrm{I}=0.5 \mu \mathrm{m}$ ).

(Figure 3(o)). Earlier B.-G. Chitwood and M. B. Chitwood [27] reported two round binucleated coelomocytes-like bodies from Cephalobellus papilliger and four rounded bodies in Blatticola blattae. Ancylostoma duodenale possesses strandlike organs with refractive particles, in the body cavity [20]. Unlike Secernenteans (Figures 4(c) and 4(g)), the coelomocytes are not conspicuous in Adenophoreans, however, the monhysterids (Figure 4(d)), araeolaimids (Figure 4(i)), chromadorids (Figure 4(h)) and few enoplids (Figures 4(a) and $4(\mathrm{~b})$ ) show prominent ovoid coelomocytes with relatively fixed positions. Coelomocytes could also be detected in few species of dorylaims (Figure 4(f)) and mononchs (Figure 4(e)).

2.2. Size. The coelomocytes in earthworms tend to be of two sizes: small (cytotoxic) and large (phagocytic) [35]. In sea urchins, coelomocytes are free-wandering cells that populate the coelomic cavity of which two-thirds are phagocytic, and the rest are vibratile cells, or colorless and red spherule cells [36].

Most descriptive studies [9, 37] have indicated that nematode coelomocytes frequently become giant cells during 

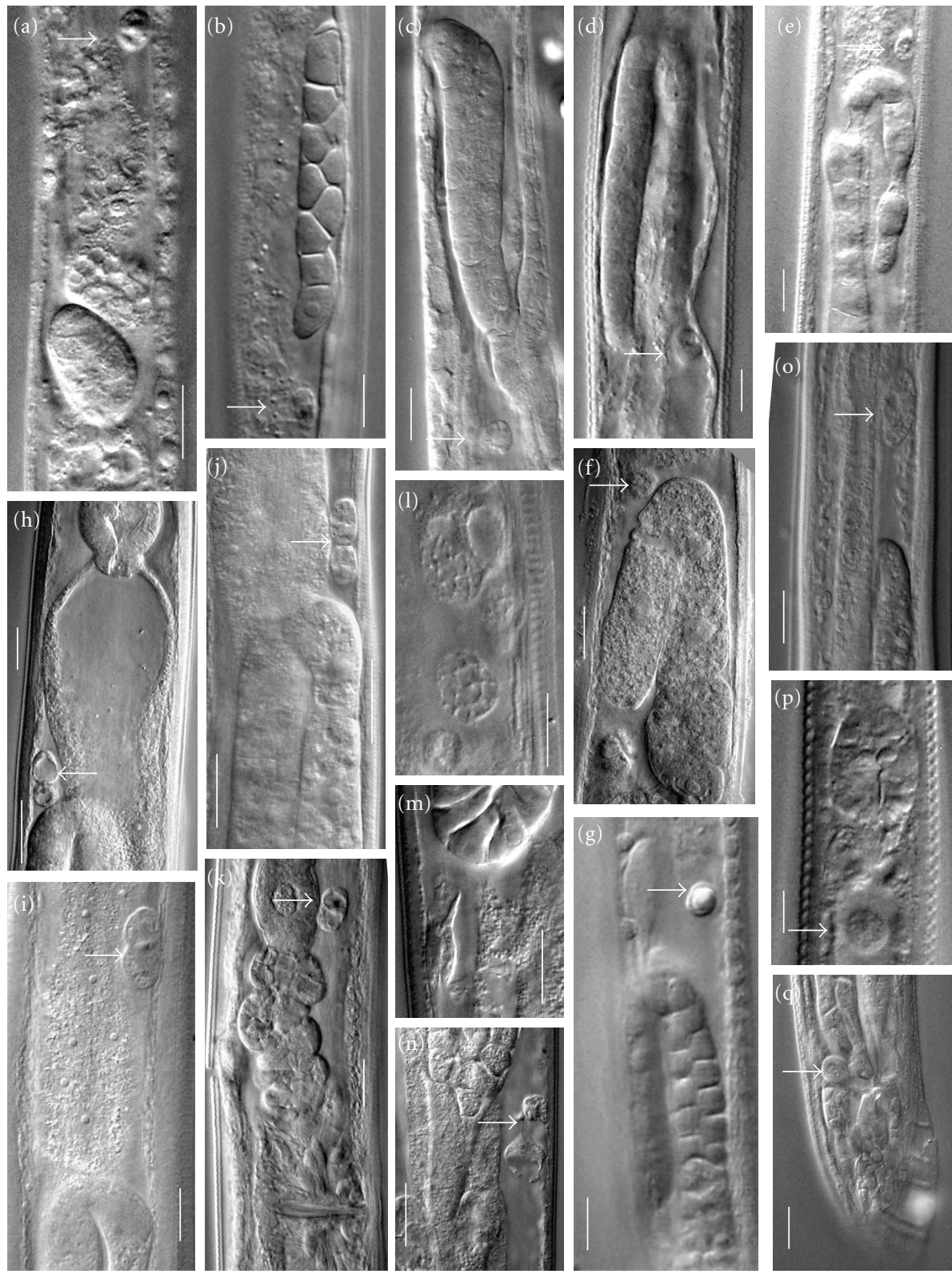

Figure 3: Position of coelomocytes with respect to developing gonad indicated by arrows. (a) Coelomocytes in second stage juvenile. (b) Coelomocyte in third stage female juvenile. (c) Coelomocyte in fourth stage female juvenile. (d), (e) Coelomocyte in adult female. (f), (g) Coelomocytes adjacent to testis in adult male. (h)-(j), (o), (p) Coelomocytes between cardia and anterior reflexed ovary. (l)-(n), (q) Coelomocytes with varied morphologies close to genital system in posterior body region (scale bar $=5 \mu \mathrm{m})$.

the parasitic phase of development, whereas in free-living species the cells remain relatively small. In C. elegans a coelomocyte is about $10-20 \mu \mathrm{m}$ in diameter whereas the large stellate pseudocoelomocyte of adult parasite, $P$. equorum, measures approximately $5 \mathrm{~mm}$ long $\times 3 \mathrm{~mm}$ wide and $250 \mu \mathrm{m}$ thick.

2.3. Number. In the purple sea urchin (Strongylocentrotus purpuratus), there are on average $7.5 \times 10^{6}$ putative coelomocytes per $\mathrm{mL}$ of coelomic fluid [38]. However, in nematodes their number is considerably smaller and varies from 2 to 6 . There are five coelomocytes in males and six in adult hermaphrodites of C. elegans [39]. In Thelastomatidae, the voluminous pseudocoel contains 3 large pseudocoelomocytes. In Sphaerolaimus gracilis, two pairs of coelomocytes occurred laterally posterior to the pharyngeointestinal junction [40]. The anterior pair of the coelomocytes between the renette cell and gonad lies on the left or the right lateral side of the body. The posterior pair of coelomocytes lies on the opposite side [41].

2.4. Structural Details. The sipunculids were investigated to possess coelomic cell complexes in the coelomic fluid, using Transmission Electron Microscopy [42]. Each complex was made of a central glandular cell and the outer layer 

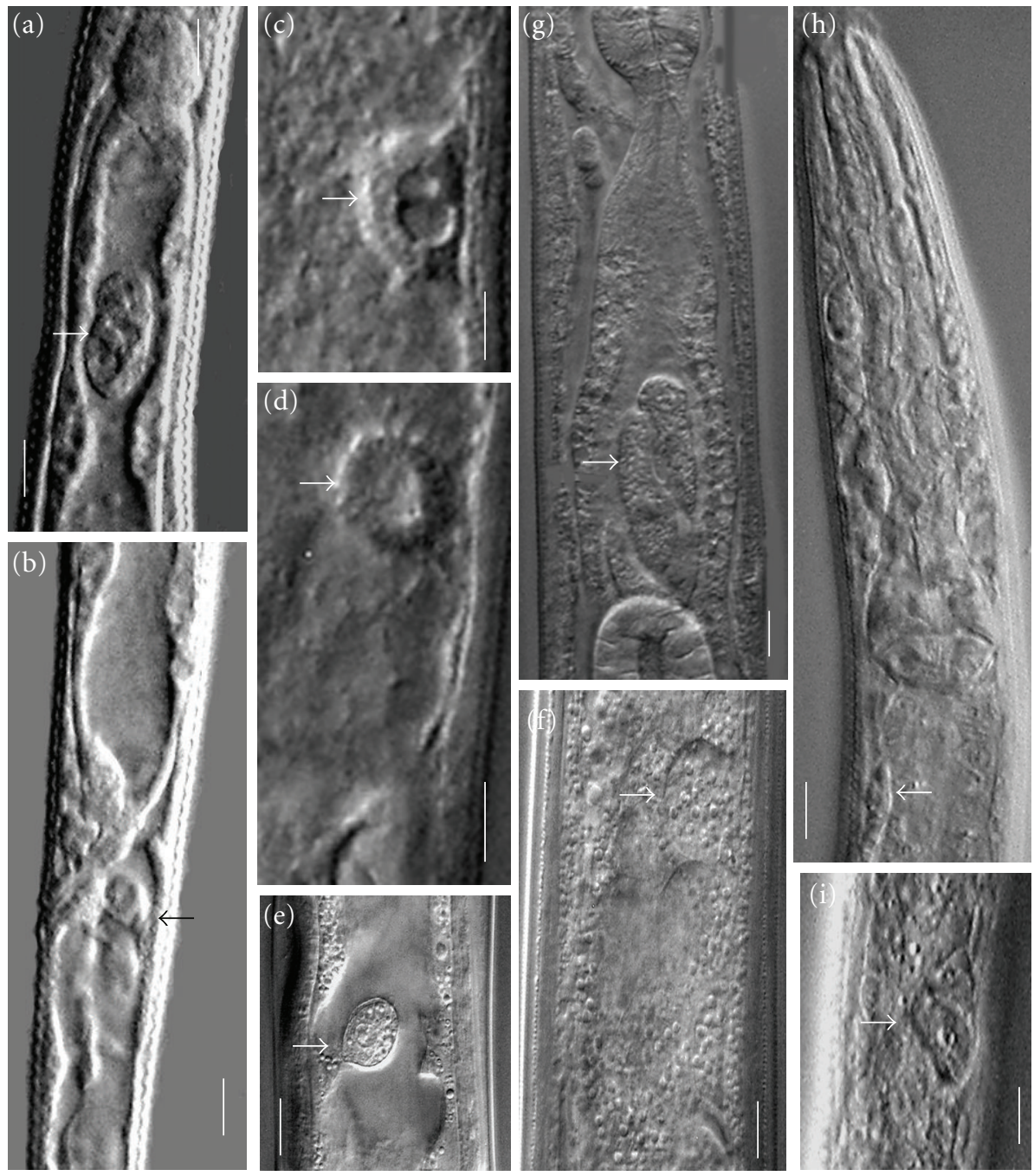

FIGURE 4: Coelomocytes in different nematode groups indicated by arrows. (a), (b) Ovoid coelomocyte in an enoplid. (c) Bipolar coelomocyte in a rhabditid. (d) Stellate coelomocyte in a monhysterid. (e) Rounded coelomocyte in a mononchid. (f) Inconspicuous coelomocyte in a dorylaim. (g) Paired spindle-shaped coelomocytes in a panagrolaimid. (h) Elongate coelomocyte in a chromadorid. (i) Binucleate coelomocyte in an araeolaimid (scale bar $=5 \mu \mathrm{m}$ ).

of podocytes. Peculiar cell complexes ("urns"), comprising ciliary and granular cells, were described in Thysanocardia nigra $[42,43]$.

In pseudocoelomate phylum Rotifera, video-enhanced differential interference contrast microscopy has revealed a network of filopodia in the pseudocoelomocytes that show motility [44]. The filopodial junctions are regularly displaced. Thereafter, the free-ending filopodia form and extend, and further show retraction. There occur enlargements, diminutions, and extinctions of filopodial polygons, and the formation of new polygons in these rotifers.

In the group Priapulida, the mesenteries that suspend organs are reported to be formed from extracellular material produced by coelomocytes or amoebocytes that move freely in the body cavity. These amoebocytes produce fibers that suspend the digestive system and other organs in pseudocoelom. Two types of coelomocytes have been observed in the body cavity of Priapulus caudatus by Mattisson and Fänge [45]. The "erythrocytes" are nucleated and contain marginal bands, vacuoles and occasionally crystals. The cytoplasm has few organelles. The "leucocytes" are amoeboid, motile cells, the cytoplasm of which contains numerous organelles.

In nematodes, the coelomocyte is a highly specialized cell containing a swollen, ramifying rough endoplasmic reticulum, which is filled with an amorphous material, and is associated with many large complex Golgi bodies. A heterogeneous population of electron-dense bodies constitutes the major cellular inclusion. These structures may represent either a product of the cell and/or material taken up by the coelomocytes [46].

In animal parasitic nematode, $P$. equorum, a large stellate cell lies in the pseudocoelom, firmly attached to the surrounding tissue [10] with a large nucleus and cytoplasm containing numerous granules and vesicles. A. suum like $P$. equorum contains a large irregular nucleus lying in a central cytoplasmic mass which branches into many amoeboid extensions [10, 20,47-49]. These extensions terminate in spherical bodies of cytoplasm that have been referred to 
as "cytoplasmic pearls" (see Hurlaux [10]). Fukuda [49] performed detailed study on the branched cell of A. suum. The transmission and scanning electron microscopic studies have elucidated finer details of coelomocytes of adult $A$. suum. The extraordinarily large cell with a main body of cytoplasm, contains a centrally located nucleus including many large nucleoli. The central cytoplasm branches extensively, and each branch ends in small bulbs composed of a fibrous core surrounded by a region containing most of the cell organelles. The branches of the coelomocytes increase the cell surface area and extend over the gut, lateral line, and body muscles. The free-floating spherical coelomocytes lying in the pseudocoelomic cavity of larvae and adult C. elegans have been found to endocytose many compounds, possibly for immune surveillance. The coelomocytes in adult hermaphrodites, often lying pairwise together, display prominent cytoplasmic inclusions and vacuoles. These coelomocytes become more granulated and vacuolated during postembryonic development of C. elegans [41].

\section{Origin and Location of Coelomocytes}

Nematode development provides an excellent model system for studying the relationships and connections between cell growth, cell division, and cellular differentiation [41, 50]. The differentiation is not evident during the early phases of cleavage program, however, at later stages, cellular populations begin to show morphological and molecular differences that reflect their final fate. Though the coelomocytes, strands, and membranes in the pseudocoelom were all considered to be a type of mesenchyme, quite early by Hyman [51], nevertheless, Maggenti [52] questioned the reliability of the fact. It has been proved now that these coelomocytes are mesodermal in origin generating from blast cells that also give rise to mesoderm. The M-lineage includes cells that form body wall muscles, coelomocytes (similar to macrophages), and sex myoblasts-precursors to vulval and uterine muscles. Coelomocyte precursors fail to differentiate in some mutants but instead undergo an extra division to generate cells that can enlarge like sex myoblasts.

Unlike annelids and echinoderms, the nematode coelomocytes are fixed in position and firmly attached to the inner surface of the body wall by filopodia (Figures 2(d), 2(e), and $2(\mathrm{~g}))$. However, aberrantly positioned coelomocytes suggest the possibility that detachment and migration may occur in some instances. The coelomocytes are usually located ventral, lateral, or even dorsal in position, in close vicinity of the genital primordium (Figure 3 ) and keep on changing their position with successive development and moulting. In adults, one or two coelomocytes definitely exist between the base of pharynx and the anterior end of gonad (Figures 3 and 4). Stefanski [26] described four round cells in Rhabditella axei, two of which were located between the base of pharynx and the anterior end of ovary/testis, one at the blind end of anterior gonad and another at (3/4)th of body length from anterior extremity.

A progenitor blast cell in the posterior part of the newly hatched larva of Nippostrongylus brasiliensis produced two coelomocytes C5 and C6 as reported by Weinstein [53]. Most sex-specific tissues of the adult are formed from the descendents of blast cells.

In C. elegans, the coelomocytes arise from two separate lineages. The six oblong celomocytes residing as 3 pairs (ventral anterior, ventral posterior, and dorsal) in the pseudocoelomic cavity adjacent to the somatic musculature of the hermaphrodite, are derived from two parts of the mesodermal lineage. Four of these coelomocytes are present at hatching and two are generated in the first larval stage. Four are born during embryogenesis from MS lineage symmetrically [50]; two are postembryonically derived from divisions of the $\mathrm{M}$ blast cell [41]. The anterior four embryonic coelomocytes are derived in pairs from progeny of two different MS grand daughters, MSap and MSpp [50], and lie on the ventral side between the pharynx and vulva. The postembryonic M-derived coelomocytes arise from divisions of $\mathrm{M}$ blast cell and do not share a common parentage [41] and reside dorsally in the tail. In males, one of the proximal germ line coelomocytes migrates posteriorly, and one $\mathrm{M}$ derived coelomocyte is formed. In first-stage juvenile (J1), destined to develop into male, one of the ventral left-side coelomocytes is located posterior to the gonad primordium rather than anterior as in J1 developing into hermaphrodite. The ventral anterior pair is located on the right side and the ventral posterior pair on the left as observed by Wood et al. [54] in C. elegans grown at $20^{\circ} \mathrm{C}$ but the positions were reversed when cultivated at $10^{\circ} \mathrm{C}$ [55]. Yanowitz and Fire [56] identified and characterized a set of mutations that affect coelomocyte number, specification, and morphology. The mutants were reported with an increased number of coelomocytes, random decrease in the number, lineagespecific decrease, and premature degradation. The lineagespecific decrease was further classified into three types: defective in both pairs of embryonic coelomocytes; defective in the MSap-derived coelomocytes; defective in the postembryonically derived coelomocytes [56]. Although many genes determining muscle cell fates have been characterized, the genes for the distinction between muscle and nonmuscle cell fates are still to be identified.

The number and position of the coelomocytes show some variations in different groups of nematodes (Figure 5) as also reported between free-living and parasitic species $[9,37]$. In a careful study, the rhabditids such as Oscheius sp. (Figure 5(a)) and Rhabditis sp. were observed to possess six small coelomocytes as found in C. elegans hermaphrodites. In the monhysterid Geomonhystera pervaga two pairs of coelomocytes were observed: one pair close to pharyngeointestinal junction while the other lying closely anterior to vulval opening (Figure 5(b)). The araeolaimid Plectus parvus possesed four relatively larger coelomocytes with the two pairs located between cardia and anterior ovary (Figure 5(c)). In Achromadora ruricola, the chromadorid was observed to have only one pair of coelomocytes in the pseudocoelom lying slightly posterior to pharyngeointestinal junction (Figure 5(d)). One pair of coelomocytes was observed to exist at the level of vulva in Prismatolaimus matoni. The two pairs of pericardial cells at the junction of pharynx and intestine showed striking similarity to 


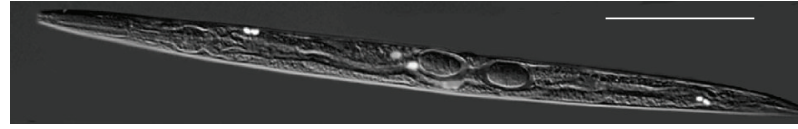

(a)

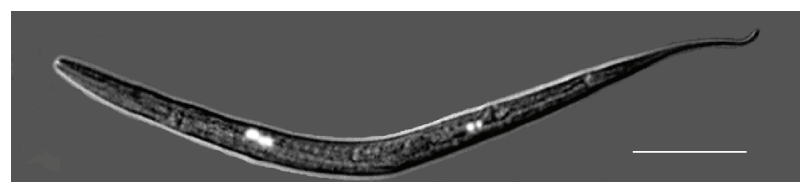

(b)

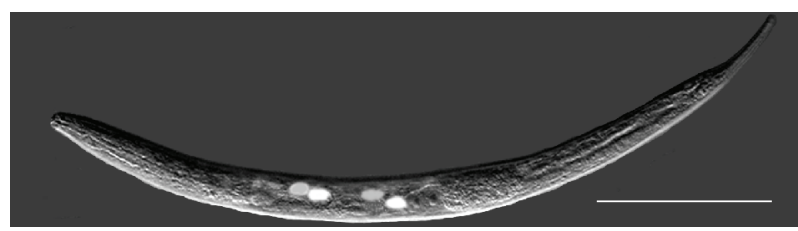

(c)

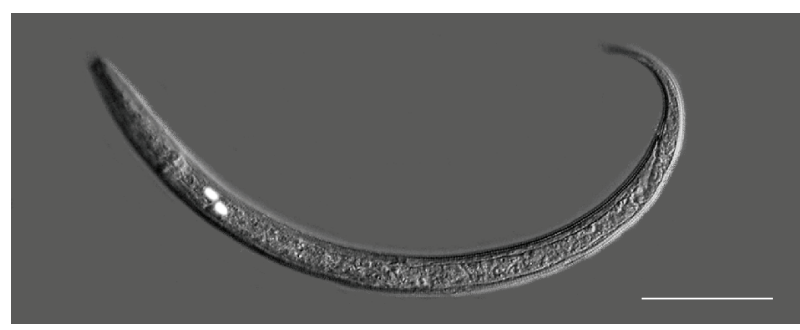

(d)

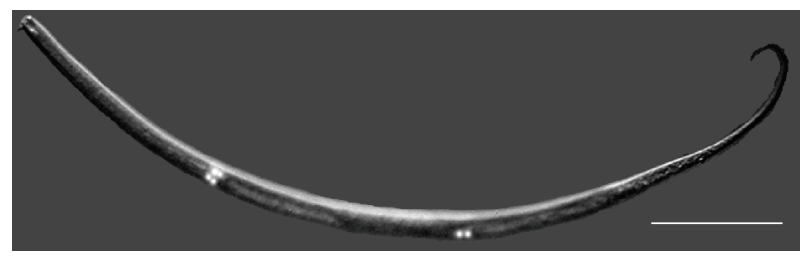

(e)

Figure 5: Number and relative positions of coelomocytes in nematodes (a) Oscheius sp. (b) Geomonhystera pervaga. (c) Plectus parvus. (d) Achromadora ruricola. (e) Prismatolaimus matoni (scale bar $=100 \mu \mathrm{m})$.

these coelomocytes in morphology and staining properties (Figure 5(e)).

\section{Changes in Coelomocytes during Developmental Cycle}

The coelomocytes in the early developmental stages are usually minute, hence cryptic and hard to recognize (Figure 3(a)). Some of the detailed researches on nematodes have indicated changes and differentiation in the pseudocoelomocytes during postembryonic development. B. G. Chitwood and M. B. Chitwood [57] stated four coelomocytes to be present in the $\mathrm{J} 1$ of most rhabditids including $C$. elegans though their number reaches 5 in males and 6 in hermaphrodites. These glandular cells are located in the pseudocoelom adjacent to the somatic musculature. In J1, their nuclei are granulated and do not contain visible nucleoli. During larval development, the cytoplasm of the coelomocytes acquires both granules (of high refractive index) and vacuoles (of low refractive index), giving these cells a very characteristic appearance. In the J1 destined to develop into hermaphrodite, four coelomocytes are located subventrally between the pharynx and the genital primordium; the two on the right are anterior to the two on the left. In the male, one of the left coelomocytes is located posterior to the gonad primordium. Weinstein $[9,37]$ studied the morphology and differentiation of the pseudocoelomocytes present in the body cavity of the second rhabditiform stage and the exsheathed third stage of $N$. brasiliensis. He reported four linearly arranged pseudocoelomocytes to be present in the newly hatched larva from the base of the pharynx to the genital primordium. They were located subventrally: the anterior two $(\mathrm{C} 1$ and $\mathrm{C} 2)$ on the right side of the ventral nerve cord, the posterior two (C3 and C4) on its left side. Another marked difference reported between the free-living rhabditiform and infective third-stage larva was the coloration of pseudocoelomocytes that changed from colorless to pink-rose hue. During the parasitic cycle the pseudocoelomocytes soon lost their pigmentation and became colorless.

Weinstein [53] further analyzed the formation and differentiation of pseudocoelomocytes in the same nematode, $N$. brasiliensis. In the first-stage larva, 7 single seam cells appeared in tandem in the hypodermis on both the right and left sides. The seam cells $1-5$ and 7 were reported to undergo two divisions and the resultant quartets maintained equal spaces. However, seam cell 6 underwent an unusual series of divisions resulting in the formation of a huge amoeboid nurse cell enclosing a quartet of small cells in a vacuole. Finally, all the seam cells along with nurse cells regressed and disappeared, except for the quartet cells that were released from their vacuole. The latter remained inactive during the life of the free-living stages. By the time, the 5th and 6th coelomocytes aligned themselves closely to seam cells 6 and their progeny; some were attached with or penetrated the nurse cells at the level of the vacuole. The coelomocytes usually were located subdorsal and posterior to the genital primordium, C5 on the right and C6 on the left.

At the time of the second molt, tiny vesicles appeared in the cytoplasm of coelomocytes 5 th and 6 th in the early third stage infective larva of $N$. brasiliensis. An increasing number of vesicles aggregated into a mass at either the anterior or posterior pole of the cells. Of the six coelomocytes, 1-4 situated anterior to the genital primordium contained larger numbers of vesicles that concentrated extraordinary amounts of vitamin B12, which was recognized as a red pigment. However, the number of vesicles remained low and the 5th and 6th coelomocytes looked colorless with absence of red pigment.

\section{Functions of Coelomocytes}

The function of coelomocytes in different groups of invertebrates has been investigated through various experiments. The immune system of the deuterostome, purple sea urchin 
(Strongylocentrotus purpuratus), is the most studied among invertebrates where numerous coelomocytes wander in the coelomic cavity [38]. About two-thirds of them are phagocytic, and the rest are vibratile cells, and colorless or red spherule cells. They tend to accumulate at sites of injury and form cellular clots to clear bacteria and other foreign substances from the coelomic cavity, and participate in allograft rejection $[38,58,59]$.

The population of echiuran worm Urechis caupo was compared by Arp et al. [60] at two sites in California, US, namely, Elkhorn Slough (a high-density site) and Bodega Bay (a high-sulfide site). The population at the latter site had greater concentrations of hematin, a nonglobin heme compound, in the coelomocytes, and exhibited a greater tolerance to sulfide in the laboratory. Therefore, it was concluded that hematin in the coelomocytes worked as a sulfide-detoxifying agent thus enhancing the survival rate of the worm.

Haug et al. [61] found that coelomocytes from the European common sea star Asterias rubens responded to trauma stress. The repair phase was observed after the first 24 hours postamputation of the arm tip, by modulating over the time the total number of circulating coelomocytes. Mangiaterra and Silva [62], through in vitro and in vivo studies, confirmed the endocytic activity of free phagocytic amoebocytes (coelomocytes) in the sea urchin that showed an ability to respond to an inflammatory stimulus.

The coelomocytes of the annelid E. fetida were classified into four major categories based on cytomorphology and cytochemistry-acidophils, basophils, chloragocytes cells, and neutrophils [63]. The enzyme acid phosphatase was present in all coelomocytes, but was especially abundant in basophils and neutrophils. Alkaline phosphatase was detected in basophils, while basophils and neutrophils actively killed the tumor target, with K562 reflecting their role in the earthworm's immune system.

Engelmann et al. [35] further demonstrated that earthworm innate immunity depended upon small and large leukocytes (coelomocytes) that synthesized and secreted humoral antimicrobial molecules (e.g., lysenin, fetidin, eiseniapore, coelomic cytolytic factor (CCF), and Lumbricin I). Coelomocytes contain several lysosomal enzymes involved in phagocytosis and a pattern recognition molecule (CCF) that may trigger the prophenoloxidase cascade, a crucial innate immune response. Earlier, Field et al. [64] studied the correlation between number of PO (Prophenoloxidase)-active coelomocytes and infection level of the parasitic protozoan Monocystis sp. in the earthworm Lumbricus terrestris that reflected a positive relationship. Such system has also been found to operate in crustaceans [65].

Even the coelomocytes of Lumbricus terrestris responded to an increase in environmental osmotic pressure from isotonic conditions $(170 \mathrm{mOsm})$ to hypertonic conditions (715 mOsm) by changing from a round/petalloid morphology to a filopodial morphology. Earthworms also show a change in number of coelomocytes in response to pollutant exposure and the normal $1: 1$ ratio of coelomocytes to eleocytes is disturbed with a rise in coelomocytes to $62 \%$, $65 \%$, and $69 \%$, respectively after $\mathrm{Cd}, \mathrm{Cu}$, and $\mathrm{Zn}$ treatments
[1]. In the earthworm Lumbricus rubellus, the polluted conditions affected the behavior of coelomocytes where copper and several other contaminants were found to impair the retention of a dye (Neutral Red) by lysosomes from coelomocytes [66]. Membrane permeability and stability are crucial factors when such soil invertebrates are exposed to freezing temperatures or desiccation thus causing substantial dehydration of the cells.

Another role attributed [63] to the coelomocytes in annelids is the homeostasis. The brown bodies in the coelomic cavity are formed from an aggregation of coelomocytes around offending foreign cells such as bacteria, gregarines, incompatible graft fragments, and altered selfstructures or necrotic muscle cells.

The function of pseudocoelomocytes in the nematodes has been debatable. Nassonov $[47,48]$ suggested that these cells were part of the excretory system; however, Hurlaux [10] showed a definite discontinuity between the excretory system and the coelomocytes. Nevertheless, Maggenti [67] suggested an excretory function in Plectus spp. These cells have been proposed to play a scavenger role, based on their ability to continuously endocytose low molecular weight dyes and proteins (e.g., GFP) and to extra cellularly accumulate larger materials from the body cavity [28, 68]. Because of their ability to take up a variety of molecules from the body cavity fluid, these cells have been suggested to act as scavenger cells [69]. The plasma membrane of coelomocytes shows active endocytosis, with multiple "omega-figures" lying in close proximity to one another [55]. In C. elegans, coelomocytes have been shown to uptake various substances from pseudocoelom such as india ink, rhodamine-dextran, fluorescein isothiocyanate (FITC)-BSA, and FITC- lipopolysaccharide from S. typhimurium [68]. Under exceptional cases, coelomocytes were induced to take up GFP-tagged yolk particles, apparently due to the presence of the GFP moiety [70] This scavenging behavior may form a part of a primitive immune surveillance function. However, this activity does not seem to be essential for the animal's survival or fertility as nematodes with toxin-ablated coelomocytes continue to grow and bear progeny [68]. Peregrine [12], Poinar and Jansson [33], and A. F. Bird and J. Bird [34] have suggested their role in secretory and endocrine functions or processes and in phagocytic, immunologic, and denitrifying activities. In some instances, they have been thought to have a secretory function or a respiratory role in the animal parasitic species [11] although there is little direct evidence for either function. The phagocytic function demonstrated for coelomocytes is their capacity to accumulate extraordinary amounts of vitamin B12 (an intensely red pigment) in animal parasitic strongylids and trichostrongylids [29, 71]. Oya and Weinstein [72] demonstrated that vitamin B12 is converted into metabolically active coenzyme from adenosylcobalamin in A. suum. These cells were also suggested to function in the synthesis and secretion of a protein product. In A. suum the accumulated products may represent either a product of the cell and/or material taken up by the coelomocytes. Coelomocytes in larger nematodes may take up dyes (methylene blue, crystal violet) and even injected bacilli or invading organisms $[28,46]$. 
Turpeenniemi [40], after studying the ultrastructure of the coelomocytes in S. gracilis, identified them to be absorptive cells. They were found to contain cell organelles, with the characteristics of lysosomes and peroxisomes and also contained crystalloids. These cell organelles were investigated using enzyme histochemical analyses and the results indicated that they contained both catalase and acid phosphatase and, therefore, were neither peroxisomes nor lysosomes [73]. These organelles were described as coelomocyte organelles (CC-organelle). Both CC-organelles and peroxisomes indicated presence of urate oxidase [73-76], an enzyme that catalyzes the oxidation of uric acid to allantoin [77]. The studies further concluded CC-organelles to be associated with formation of vacuoles that contained catalase enzyme. Turpeenniemi [40] also observed the body-cavity fluid to be transported in pinocytotic vesicles to the vacuoles and suggested the role of these cells in purine degradation and as important centers of intermediary metabolism in nematodes.

Earthworms and other invertebrates possess natural, nonspecific, nonclonal, and nonanticipatory immune response influenced by germ line genes [35]. Coelomocytes of individual sea urchins express multiple scavenger receptor cysteine-rich (SRCR) genes from among a multigene family in diverse transcription profiles. Various immunological assays revealed presence of special proteins in different vertebrates. Nevertheless, the invertebrates are also reported to possess two coelomocyte proteins homologous to factor $\mathrm{B}$ and $\mathrm{C} 3 / \mathrm{C} 4 / \mathrm{C} 5$ complement proteins in vertebrates [59, 78, 79]. Coelomocytes displayed transcriptional response to injury [80]. TOLL and TOLL-like receptor signaling is essential for phagocytosis and antimicrobial peptide synthesis and secretion in insects and vertebrates. Dewilde et al. [81] stated that Mb1-like tissue globins occur intracellularly in circulating "coelomocytes" and extracellularly dissolved in the haemolymph in molluscs and annelids.

The nematode $C$. elegans has recently been used as an attractive model system $[82,83]$ to gain insight into mechanisms of immunity in invertebrate organisms. However, there appears a lineage-specific loss of innate immune mechanisms in C. elegans [84]. The hypothesis is supported by the fact that although its genome encodes a number of homologs of Toll pathway components, these genes appear not to contribute directly to immunity $[85,86]$. The nematode is found to be equipped with the antimicrobial and digestive peptides, a transforming growth factor b-like pathway, an insulin receptor-like pathway, a programmed cell death (PCD) pathway, and finally three MAP kinase pathways (p38 MAP kinase). These pathways play important roles in various developmental processes and interact with each other and most of them also respond to stress conditions, suggesting that the nematode uses elements of stress response as part of its inducible immune defense against pathogens. Interestingly, nematodes appear to be free from diseases caused by viruses possibly due to the reason that the worms may use RNAi (RNA interference) as an antiviral defense [87].

As many parts of the more complex innate systems of insects and vertebrates show enormous similarities (e.g., components of cellular defenses or the Toll pathways), these are likely to have a single origin. In C. elegans the coelomocytes may serve certain immune or hepatic functions.

However, unlike immune cells in other organisms, the coelomocytes are not migratory; rather, they are attached to the hypodermis, and would rely on the movement of the animal to bring foreign agents into their proximity. These cells, however, show high endocytotic activity, and may still contribute to immunity by supporting detoxification processes [68].

A combination of forward and reverse genetics has identified a number of new membrane trafficking factors. Most of them have mammalian homologues which function in the same transport events.

SAND genes have been found to be of special importance in this connection. They are present in major eukaryotic taxa, with two SAND genes in vertebrate species. SAND proteins are ancient and belong to an absolutely distinct protein family. Poteryaev and Spang [88] described a gene sand-1, the malfunction of which causes profound endocytic defects in many tissues of $C$. elegans. The most conspicuous feature of sand-1 (or 552) mutants is the presence of large intracellular membrane-bounded granules in the early embryo. In coelomocytes, this led to accumulation of extremely large vacuoles of endocytic origin.

\section{Conclusions}

The invertebrate immune mechanisms can be varied and diverse with the different key players being the antimicrobial peptides, RNA interference, phagocytic cells/cytolytic cells, lysozymes, production of toxic oxygen, and nitrogen metabolites or the most advanced defense mechanisms utilizing the $\mathrm{C} 3$ and Toll receptors. The interaction between invertebrate model hosts and pathogens provides insights into the mechanisms of pathogen virulence and host immunity, and complements the use of mammalian models by enabling whole-animal high throughput infection assays [89]. Each alternative model system has advantages and disadvantages, which emphasize the need to use many models to understand the mechanisms by which pathogens manipulate the innate immune system to cause diseases.

D. melanogaster and C. elegans have been used successfully to study microbial pathogenesis and defense responses. However, there are some limitations as both cannot survive at $37^{\circ} \mathrm{C}$ and the inoculation dose of antimicrobial substances is technically challenging in these systems [90]. In addition, there are many differences in the innate immune systems of invertebrates and vertebrates, for example, the recognition mechanism by Toll receptors seems to be lacking in $C$. elegans. Despite the differences, C. elegans is being used as a model system [91] due to extensive genetic and molecular information available facilitating an in-depth analysis of host defense factors and pathogen virulence factors. Many of these factors are conserved of insects and mammals, indicating the relevance of the nematode model for vertebrate innate immune responses. The nematode has been found to exhibit protective responses to a variety of fungal and bacterial pathogens; however, it lacks the cellular arm of innate 
immunity in its classic form. Although coelomocytes are present (five in males and six in hermaphrodites), but are not involved in phagocytosis or encapsulation of bacteria as seen in diverse invertebrate species.

Coelomocytes also regarded as nonmobile scavenger cells continuously and nonspecifically endocytose fluid from the pseudocoelom (body cavity) although toxin-mediated ablation of coelomocytes indicated that endocytosis is not essential for growth or survival of $C$. elegans under normal laboratory conditions. However, there exists rather a complex link of intracellular signaling cascades contributing to the antibacterial defenses of $C$. elegans [92]. Another indication is that intercellular communication between different cell types plays a role in worm innate immunity. Four signaling pathways involved in immune responses have been identified so far: the p38 MAP kinase pathway, the programed cell death pathway, the TGF- $\beta$ pathway, and the DAF-2 insulin/IGF-I like signaling pathway. The signaling pathways and the effectors produced depend on the type of infection, indicating the nematode's ability to detect and distinguish between infecting micro-organisms. ILR (insulin-like receptors) pathway plays an important role into both resistance and avoidance behavior against a potentially natural pathogen. ILR signaling also contributes to physiological resistance against diverse stressors including heavy metals, hypoxia [93], and so forth. However, the molecules involved in recognition of pathogens or stresses are yet to be identified. The various proteins encoded in genome, such as those with C-type lectin domains, may have this recognition function.

Recently, coelomocytes have been used in pollution studies for detection of stress [94]. Coelomocytes in earthworms exposed to heavy metals exhibited significant impairment of pinocytosis and plastic adherence [95]. Nematodes of the ideal bioindicators, in view of their ubiquity and hardy nature, can be tested for such studies to detect stress at cellular as well as molecular levels and its impacts on coelomocytes, if any. Although the understanding of $C$. elegans defenses is developing rapidly, future work is needed to analyze how infection is perceived by the nematode, what are the types of responses triggered by different pathogens, or by stress, despite the fact that they involve linked signaling cascades. The tractability and relative simplicity of C. elegans are important to understand the complexity of conserved innate immune defenses, and to explain the role of cellular stress in response to infection.

\section{Acknowledgment}

The financial assistance by Department of Science and Technology (DST) and Ministry of Environment and Forests (MOEF), New Delhi, is acknowledged here with thanks.

\section{References}

[1] E. L. Cooper, "Comparative immunology," Invertebrate Zoology, vol. 1, pp. 32-43, 2006.

[2] S.-C. Sun, I. Lindstrom, H. G. Boman, I. Faye, and O. Schmidt, "Hemolin: an insect-immune protein belonging to the immunoglobulin superfamily," Science, vol. 250, no. 4988, pp. 1729-1732, 1990.

[3] M. Anastassova-Kristeva, "The origin and development of the immune system with a view to stem cell therapy," Journal of Hematotherapy and Stem Cell Research, vol. 12, no. 2, pp. 137154, 2003.

[4] P. Sima, "Annelid coelomocytes and hematocytes: roles in cellular immune reactions," in Immunology of Annelids, V. Větvička, E. L. Cooper, M. Bilej, and P. Roch, Eds., pp. 115165, CRC Press, Boca Raton, Fla, USA, 1993.

[5] G. G. Martin, C. T. Oakes, H. R. Tousignant, H. Crabtree, and R. Yamakawa, "Structure and function of haemocytes in two marine gastropods, Megathura crenulata and Aplysia californica," Journal of Molluscan Studies, vol. 73, no. 4, pp. 355-365, 2007.

[6] M. H. Ravindranath, "Haemocytes in haemolymph coagulation of arthropods," Biological Reviews, vol. 55, no. 2, pp. 139170, 2008.

[7] Z. Gliński and J. Jarosz, "Immune phenomena in echinoderms," Archivum Immunologiae et Therapiae Experimentalis, vol. 48, no. 3, pp. 189-193, 2000.

[8] R. Muñoz-Chápuli, R. Carmona, J. A. Guadix, D. Macías, and J. M. Pérez-Pomares, "The origin of the endothelial cells: an evo-devo approach for the invertebrate/vertebrate transition of the circulatory system," Evolution and Development, vol. 7, no. 4, pp. 351-358, 2005.

[9] P. P. Weinstein, "Morphology and differentiation of the coelomocytes of the free-living stages of Nippostrongylus brasiliensis," The Journal of Parasitology, vol. 84, no. 4, pp. 730738, 1998.

[10] R. Hurlaux, "Recherches sur les cellules dites phagocytaires de l'ascaride du cheval (Parascaris equorum Goeze)," Annales des Sciences Naturelles Zoologie, vol. 11, pp. 155-225, 1947.

[11] P. P. Weinstein, "Excretory mechanisms and excretory products of nematodes: an appraisal," in Host Influence on Parasite Physiology, L. A. Stauber, Ed., pp. 65-92, Rutgers University Press, New Brunswick, NJ, USA, 1960.

[12] P. C. Peregrine, "Observations on arcade cells and pseudocoelomocytes in some oxyuroid nematodes parasitic in cockroaches," Parasitology, vol. 66, pp. 165-180, 1973.

[13] L. H. Bojanus, "Enthelminthica," in Isis (Oken), vol. 1, pp. 184-190, Jena, India, 1821.

[14] E. Bugnion, "Note sur les globules sanguins du Mermis aquatilis Duj. suivie de quelques remarques sur la structure anatomique de cette espèce," Actes de la Société Helvétique des Sciences Naturelles, vol. 60, pp. 247-255, 1878.

[15] O. von Linstow, "Bericht über die wissenschaftlichen Leistungen in der Naturgeschichte der Helminthen im Jahre 1893," Archiv für Naturgeschichte, vol. 60, no. 2, p. 230, 1899.

[16] L. A. Jägerskiöld, "Betrage zur Kenntnis der Nematoden," Zoologische Jahrbuecher Abteilung für Anatomie, vol. 7, pp. 449-532, 1894.

[17] L. A. Jägerskiöld, "Über die büschelförmigen Organe bei Ascaris Arten," Centralblatt für Bakteriologie und Parasitenkunde, vol. 24, pp. 737-741, 1898.

[18] L. A. Jägerskiöld, "Weitere Beiträge zur Kenntnis der Nematoden," Kongliga Svenska Vetenskaps Academien Handlingar, vol. 35, pp. 1-80, 1901.

[19] N. Nassonov, "Sur les organes du systeme excreteur des Ascarides et des oxyurides," Zoologischer Anzeiger, vol. 20, pp. 202-205, 1897.

[20] N. Nassonov, "Zur Kenntnis der phagocytären Organe bei den parasitischen Nematoden," Archiv für Mikroskopische Anatomie, vol. 55, no. 1, pp. 488-513, 1900. 
[21] A. E. Shipley, "Note on the excretory cells of Ascaridae," Zoologischer Anzeiger, vol. 20, p. 342, 1897.

[22] M. Rauther, Beiträge zur Kenntnis von Mermis albicans v. Sieb, M.S. thesis, Jena, G. Fischer, Stuttgart, Germany, 1906.

[23] E. Martini, "Die Anatomie der Oxyuris curvula," Zeitschrift für wissenschaftliche Zoologie, vol. 116, pp. 137-534, 1916.

[24] E. Martini, "Zur Anatomie der Vorderendes von Oxyuris robusta," Archiv für Schiffs- und Tropen-Hygiene, vol. 30, pp. 491-503, 1926.

[25] R. Höppli, "Über das vorderende der Ascariden," Zeitschrift für Zellforschung und Mikroskopische Anatomie, vol. 2, no. 1, pp. $1-68,1925$.

[26] W. Stefanski, "Exerétion chez les nematodes libres," Arch. Nauk. iBol. Towarz Nauk. Warszaw, vol. 1, pp. 1-33, 1922.

[27] B.-G. Chitwood and M. B. Chitwood, "The histological anatomy of cephalobellus papilliger Cobb, 1920," Zeitschrift für Zellforschung und Mikroskopische Anatomie, vol. 19, no. 2, pp. 309-355, 1933.

[28] B. G. Chitwood and M. B. Chitwood, An Introduction to Nematology, Monumental Printing, Baltimore, Md, USA, 1950.

[29] P. P. Weinstein, "Some relations of B12-synthesizing bacteria to nematodes," The Journal of Parasitology, vol. 51, p. 55, 1965.

[30] F. W. Douvres, F. G. Tromba, and G. M. Malakatis, "Morphogenesis and migration of Ascaris suum larvae developing to fourth stage in swine," The Journal of Parasitology, vol. 55, no. 4, pp. 689-712, 1969.

[31] A. D. Boghen and K. G. Davey, "A pseudocoelomocyte in the parasitic nematode Phocanema decipiens," Transactions of the American Microscopical Society, vol. 94, no. 2, pp. 203-210, 1975.

[32] M. Ishikawa, "Cytological studies on the bushy cells in the pig Ascaris (Ascaris suum). I. Ultrastructure and secretory function," Japanese Journal of Parasitology, vol. 25, no. 2, pp. 109-125, 1976.

[33] G. O. J. Poinar and H. B. Jansson, Diseases of Nematodes, CRC Press, Boca Raton, Calif, USA, 1988.

[34] A. F. Bird and J. Bird, The Structure of Nematodes, Academic Press, San Diego, Calif, USA, 2nd edition, 1991.

[35] P. Engelmann, E. L. Cooper, and P. Németh, "Anticipating innate immunity without a Toll," Molecular Immunology, vol. 42, no. 8, pp. 931-942, 2005.

[36] J. C. S. Borges, B. E. Jensch-Junior, P. A. G. Garrido, M. B. B. C. D. Mangiaterra, and J. R. M. C. Silva, "Phagocytic amoebocyte sub populations in the perivisceral coelom of the sea urchin Lytechinus variegatus (Lamarck, 1816)," Journal of Experimental Zoology Part A, vol. 303, no. 3, pp. 241-248, 2005.

[37] P. P. Weinstein, "Vitamin B12 changes in Nippostrongylus brasiliensis in its free-living and parasitic habitats with biochemical implications," The Journal of Parasitology, vol. 82, no. 1, pp. 1-6, 1996.

[38] Z. Pancer, "Dynamic expression of multiple scavenger receptor cysteine-rich genes in coelomocytes of the purple sea urchin," Proceedings of the National Academy of Sciences of the United States of America, vol. 97, no. 24, pp. 13156-13161, 2000.

[39] J. White, "The anatomy," in The Nematode Caenorhabditis elegans, W. B. Wood, Ed., pp. 81-122, Cold Spring Harbor Laboratory, W. B. Cold Spring Harbor, NY, USA, 1988.

[40] T. A. Turpeenniemi, "Ultrastructure of coelomocytes in Sphaerolaimus gracilis de Man, 1876 (Nematoda)," Journal of Nematology, vol. 25, no. 4, pp. 616-624, 1993.
[41] J. E. Sulston and H. R. Horvitz, "Post embryonic cell lineages of the nematode. Caenorhabditis elegans," Developmental Biology, vol. 56, no. 1, pp. 110-156, 1977.

[42] A. S. Maiorova and A. V. Adrianov, "Ultrastructure of tentacles in the sipunculid worm Thysanocardia nigra Ikeda, 1904 (sipuncula)," Russian Journal of Marine Biology, vol. 31, no. 1, pp. 21-27, 2005.

[43] A. S. Maiorova and A. V. Adrianov, "Free-swimming Cellular Complexes in the Coelom of the Sipunculid Thysanocardia nigra Ikeda, 1904 (Sipuncula)," Russian Journal of Marine Biology, vol. 29, no. 3, pp. 180-184, 2003.

[44] O. Baumann, K. Arlt, K. Römmling, H. Goller, and B. Walz, "Characterization of an extremely motile cellular network in the rotifer Asplanchna spp. Structure, kinetics, and the cytoskeleton," Cell and Tissue Research, vol. 299, no. 1, pp. 159-172, 2000.

[45] A. Mattisson and R. Fänge, "Ultrastructure of erythrocytes and leucocytes of Priapulus caudatus (de Lamarck) (Priapulida)," Journal of Morphology, vol. 140, no. 3, pp. 367-379, 1973.

[46] R. I. Bolla, P. P. Weinstein, and G. D. Cain, "Fine structure of the coelomocyte of adult Ascaris suum," The Journal of Parasitology, vol. 58, no. 6, pp. 1025-1036, 1972.

[47] N. Nassonov, "Sur les glandes terminaux des cellules excreteurs de Mr. Hamann chez les ascarides," Zoologischer Anzeiger, vol. 21, pp. 48-50, 1898.

[48] N. Nassonov, "Sur les organes phagocytaires chez Strongylus armatus," Zoologischer Anzeiger, vol. 20, pp. 202-205, 1898.

[49] T. Fukuda, "Electron microscopical studies on stellate cells of Ascaris lumbricoides," Journal of Numamoto Medical Society, vol. 35, pp. 889-907, 1961.

[50] J. E. Sulston, E. Schierenberg, J. G. White, and J. N. Thomson, "The embryonic cell lineage of the nematode Caenorhabditis elegans," Developmental Biology, vol. 100, no. 1, pp. 64-119, 1983.

[51] L. H. Hyman, Invertebrates: Platyhelminthes and Rhynchocoela, McGraw-Hill, New York, NY, USA, 1951.

[52] A. R. Maggenti, "Nemic relationships and the origin of plant parasitic nematodes," in Plant Parasitic Nematodes, B. M. Zuckerman, W. F. Mai, and R. A. Rohde, Eds., pp. 65-81, Academic Press, New York, NY, USA, 1971.

[53] P. P. Weinstein, "The origin of coelomocytes 5 and 6 and their interaction with a seam nurse cell in the free-living stages of Nippostrongylus brasiliensis," The Journal of Parasitology, vol. 90, no. 6, pp. 1308-1320, 2004.

[54] W. B. Wood, D. Bergmann, and A. Florance, "Maternal effect of low temperature on handedness determination in C. elegans embryos," Developmental Genetics, vol. 19, no. 3, pp. 222-230, 1996.

[55] Z. F. Altun and D. H. Hall, "Introduction to C. elegans anatomy," in Handbook of C. Elegans Anatomy, WormAtlas, 2005, http://www.wormatlas.org/handbook/contents.htm.

[56] J. Yanowitz and A. Fire, "Cyclin D involvement demarcates a late transition in C. elegans embryogenesis," Developmental Biology, vol. 279, no. 1, pp. 244-251, 2005.

[57] B. G. Chitwood and M. B. Chitwood, An Introduction to Nematology, Park Press Baltimore: Monumental Printing, Baltimore, Md, USA, 1974.

[58] L. C. Smith, R. J. Britten, and E. H. Davidson, "Lipopolysaccharide activates the sea urchin immune system," Developmental and Comparative Immunology, vol. 19, no. 3, pp. 217-224, 1995.

[59] L. C. Smith, C.-S. Shih, and S. G. Dachenhausen, "Coelomocytes express SpBf, a homologue of factor B, the second 
component in the sea urchin complement system," The Journal of Immunology, vol. 161, no. 12, pp. 6784-6793, 1998.

[60] A. J. Arp, B. M. Hansen, and D. Julian, "Burrow environment and coelomic fluid characteristics of the echiuran worm Urechis caupo from populations at three sites in northern California," Marine Biology, vol. 113, no. 4, pp. 613-623, 1992.

[61] T. Haug, A. K. Kjuul, O. B. Styrvold, E. Sandsdalen, Ø. M. Olsen, and K. Stensvåg, "Antibacterial activity in Strongylocentrotus droebachiensis (Echinoidea), Cucumaria frondosa (Holothuroidea), and Asterias rubens (Asteroidea)," Journal of Invertebrate Pathology, vol. 81, no. 2, pp. 94-102, 2002.

[62] M. B. B. C. D. Mangiaterra and J. R. M. C. Silva, "Induced inflammatory process in the sea urchin Lytechinus variegatus," Invertebrate Biology, vol. 120, no. 2, pp. 178-184, 2001.

[63] P. Valembois, M. Lassègues, and P. Roch, "Formation of brown bodies in the coelomic cavity of the earthworm Eisenia fetida andrei and attendant changes in shape and adhesive capacity of constitutive cells," Developmental and Comparative Immunology, vol. 16, no. 2-3, pp. 95-101, 1992.

[64] S. G. Field, J. Kurtz, E. L. Cooper, and N. K. Michiels, "Evaluation of an innate immune reaction to parasites in earthworms," Journal of Invertebrate Pathology, vol. 86, no. 1-2, pp. 45-49, 2004.

[65] L. Cerenius and K. Söderhäll, "Crustacean immunity and complement; a premature comparison?” American Zoologist, vol. 35, no. 1, pp. 60-67, 1995.

[66] J. M. Weeks and C. Svendsen, "Neutral red retention by lysosomes from earthworm (Lumbricus rubellus) coelomocytes: a simple biomarker of exposure to soil copper," Environmental Toxicology and Chemistry, vol. 15, no. 10, pp. 1801-1805, 1996.

[67] A. R. Maggenti, "Morphology and biology of the genus Plectus (nematode: Plectidae)," Proceedings of the Helminthological Society of Washington, vol. 28, pp. 118-130, 1961.

[68] H. Fares and I. Greenwald, "Genetic analysis of endocytosis in Caenorhabditis elegans: coelomocyte uptake defective mutants," Genetics, vol. 159, no. 1, pp. 133-145, 2001.

[69] H. Fares and B. Grant, "Deciphering endocytosis in Caenorhabditis elegans," Traffic, vol. 3, no. 1, pp. 11-19, 2002.

[70] M.-C. Paupard, A. Miller, B. Grant, D. Hirsh, and D. H. Hall, "Immuno-EM localization of GFP-tagged yolk proteins in $C$. elegans using microwave fixation," Journal of Histochemistry and Cytochemistry, vol. 49, no. 8, pp. 949-956, 2001.

[71] J. Barrett, Biochemistry of Parasitic Helminthes, Macmillan, London, UK, 1981.

[72] H. Oya and P. P. Weinstein, "Demonstration of cobamide coenzyme in Ascaris suum," Comparative Biochemistry and Physiology, vol. 50, no. 3, pp. 435-442, 1975.

[73] C. De Duve and P. Baudhuin, "Peroxisomes (microbodies and related particles)," Physiological Reviews, vol. 46, no. 2, pp. 323-357, 1966.

[74] Z. Hruban and H. Swift, "Uricase: localization in hepatic microbodies," Science, vol. 146, no. 3649, pp. 1316-1318, 1964.

[75] Z. Hruban and M. Rechcigl, Microbodies and Related Particles. Morphology, Biochemistry and Physiology, Academic Press, New York, NY, USA, 1969.

[76] N. E. Tolbert and E. Essner, "Microbodies: peroxisomes and glyoxysomes," The Journal of Cell Biology, vol. 91, no. 3, pp. 271-283, 1981.

[77] J. Keilin, "The biological significance of uric acid and guanine excretion," Biological Reviews, vol. 34, no. 3, pp. 265-294, 1959.
[78] L. C. Smith, L. Chang, R. J. Britten, and E. H. Davidson, "Sea urchin genes expressed in activated coelomocytes are identified by expressed sequence tags: complement homologues and other putative immune response genes suggest immune system homology within the deuterostomes," The Journal of Immunology, vol. 156, no. 2, pp. 593-602, 1996.

[79] W. Z. Al-Sharif, J. O. Sunyer, J. D. Lambris, and L. C. Smith, "Sea urchin coelomocytes specifically express a homologue of the complement component C3," The Journal of Immunology, vol. 160, no. 6, pp. 2983-2997, 1998.

[80] Z. Pancer, J. P. Rast, and E. H. Davidson, "Origins of immunity: transcription factors and homologues of effector genes of the vertebrate immune system expressed in sea urchin coelomocytes," Immunogenetics, vol. 49, no. 9, pp. 773-786, 1999.

[81] S. Dewilde, M. Blaxter, M. L. Van Hauwaert, et al., "Globin and globin gene structure of the nerve myoglobin of Aphrodite aculeata," Journal of Biological Chemistry, vol. 271, no. 33, pp. 19865-19870, 1996.

[82] M. J. Gravato-Nobre and J. Hodgkin, "Caenorhabditis elegans as a model for innate immunity to pathogens," Cellular Microbiology, vol. 7, no. 6, pp. 741-751, 2005.

[83] D. H. Kim and F. M. Ausubel, "Evolutionary perspectives on innate immunity from the study of Caenorhabditis elegans," Current Opinion in Immunology, vol. 17, no. 1, pp. 4-10, 2005.

[84] H. Schulenburg, C. Léopold Kurz, and J. J. Ewbank, "Evolution of the innate immune system: the worm perspective," Immunological Reviews, vol. 198, pp. 36-58, 2004.

[85] N. Pujol, E. M. Link, L. X. Liu, et al., "A reverse genetic analysis of components of the Toll signaling pathway in Caenorhabditis elegans," Current Biology, vol. 11, no. 11, pp. 809-821, 2001.

[86] A. Aballay, E. Drenkard, L. R. Hilbun, and F. M. Ausubel, "Caenorhabditis elegans innate immune response triggered by Salmonella enterica requires intact LPS and is mediated by a MAPK signaling pathway," Current Biology, vol. 13, no. 1, pp. 47-52, 2003.

[87] N. L. Vastenhouw and R. H. A. Plasterk, "RNAi protects the Caenorhabditis elegans germline against transposition," Trends in Genetics, vol. 20, no. 7, pp. 314-319, 2004.

[88] D. Poteryaev and A. Spang, "A role of SAND-family proteins in endocytosis," Biochemical Society Transactions, vol. 33, no. 4, pp. 606-608, 2005.

[89] E. Mylonakis, A. Casadevall, and F. M. Ausubel, "Exploiting amoeboid and non-vertebrate animal model systems to study the virulence of human pathogenic fungi," PLoS Pathogens, vol. 3, no. 7, article e101, pp. 1-7, 2007.

[90] E. Mylonakis and A. Aballay, "Worms and flies as genetically tractable animal models to study host-pathogen interactions," Infection and Immunity, vol. 73, no. 7, pp. 3833-3841, 2005.

[91] J. R. Powell and F. M. Ausubel, "Models of Caenorhabditis elegans infection by bacterial and fungal pathogens," Methods in Molecular Biology, vol. 415, pp. 403-427, 2008.

[92] A. C. M. Millet and J. J. Ewbank, "Immunity in Caenorhabditis elegans," Current Opinion in Immunology, vol. 16, no. 1, pp. 49, 2004.

[93] M. Hasshoff, C. Böhnisch, D. Tonn, B. Hasert, and H. Schulenburg, "The role of Caenorhabditis elegans insulin-like signaling in the behavioral avoidance of pathogenic Bacillus thuringiensis," The FASEB Journal, vol. 21, no. 8, pp. 18011812, 2007.

[94] V. Matranga, A. Pinsino, M. Celi, et al., "Monitoring chemical and physical stress using sea urchin immune cells," Progress in Molecular and Subcellular Biology, vol. 39, pp. 85-110, 2005. 
[95] J. Homa, M. Niklinska, and B. Plytycz, "Effect of heavy metals on coelomocytes of the earthworm Allolobophora chlorotica: the 7th international symposium on earthworm ecology . Cardiff · Wales · 2002," Pedobiologia, vol. 47, no. 5-6, pp. 640645, 2003. 

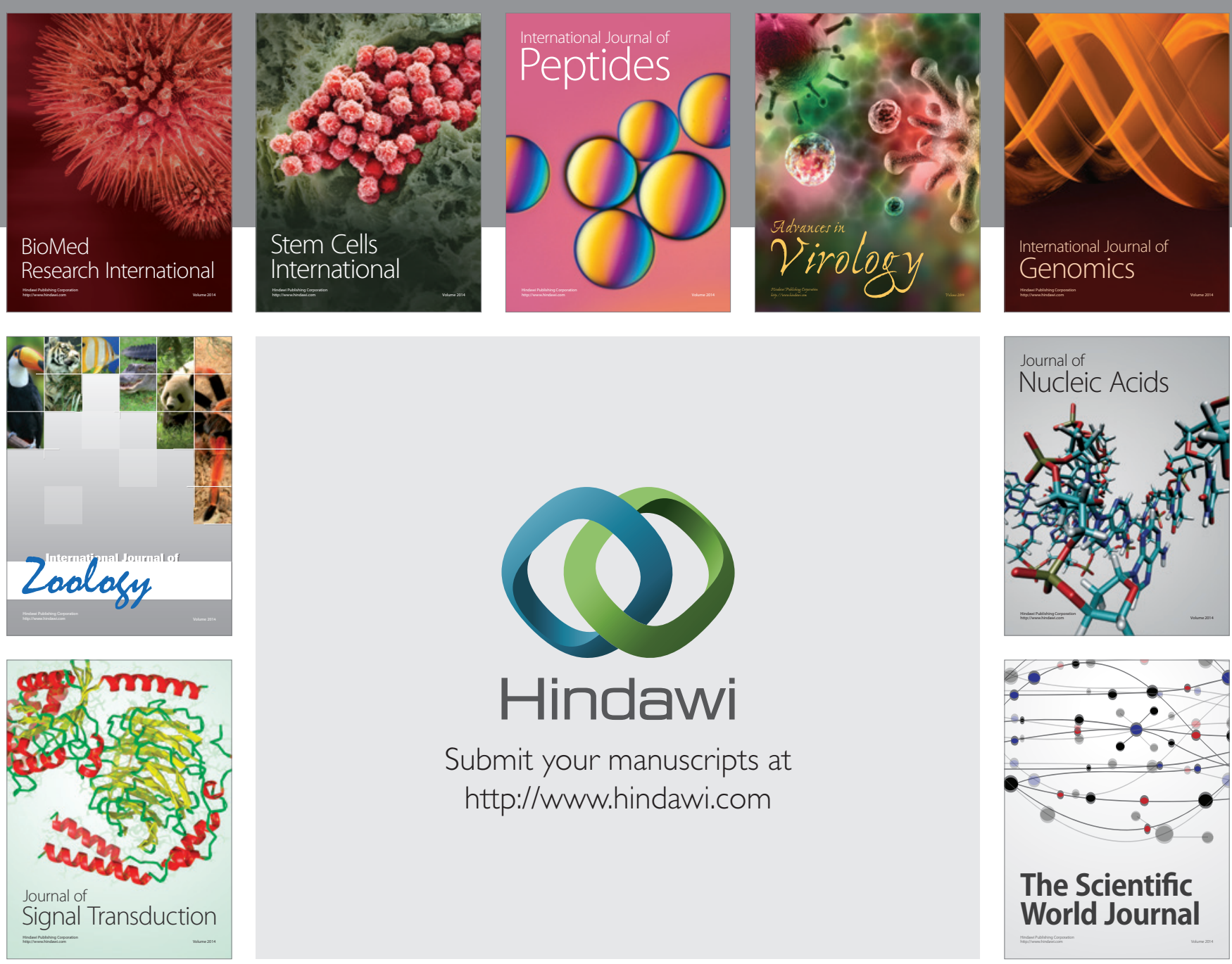

Submit your manuscripts at

http://www.hindawi.com
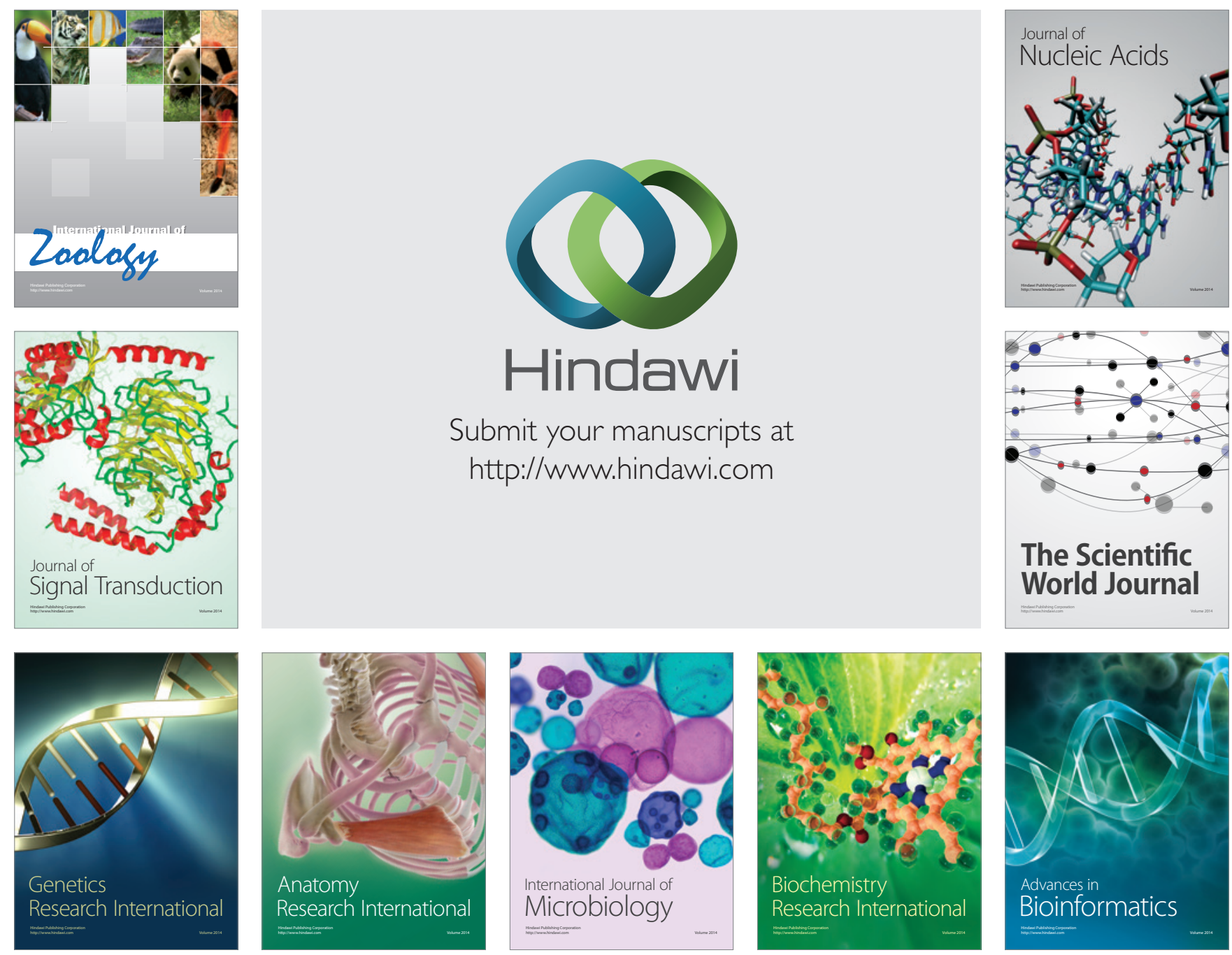

The Scientific World Journal
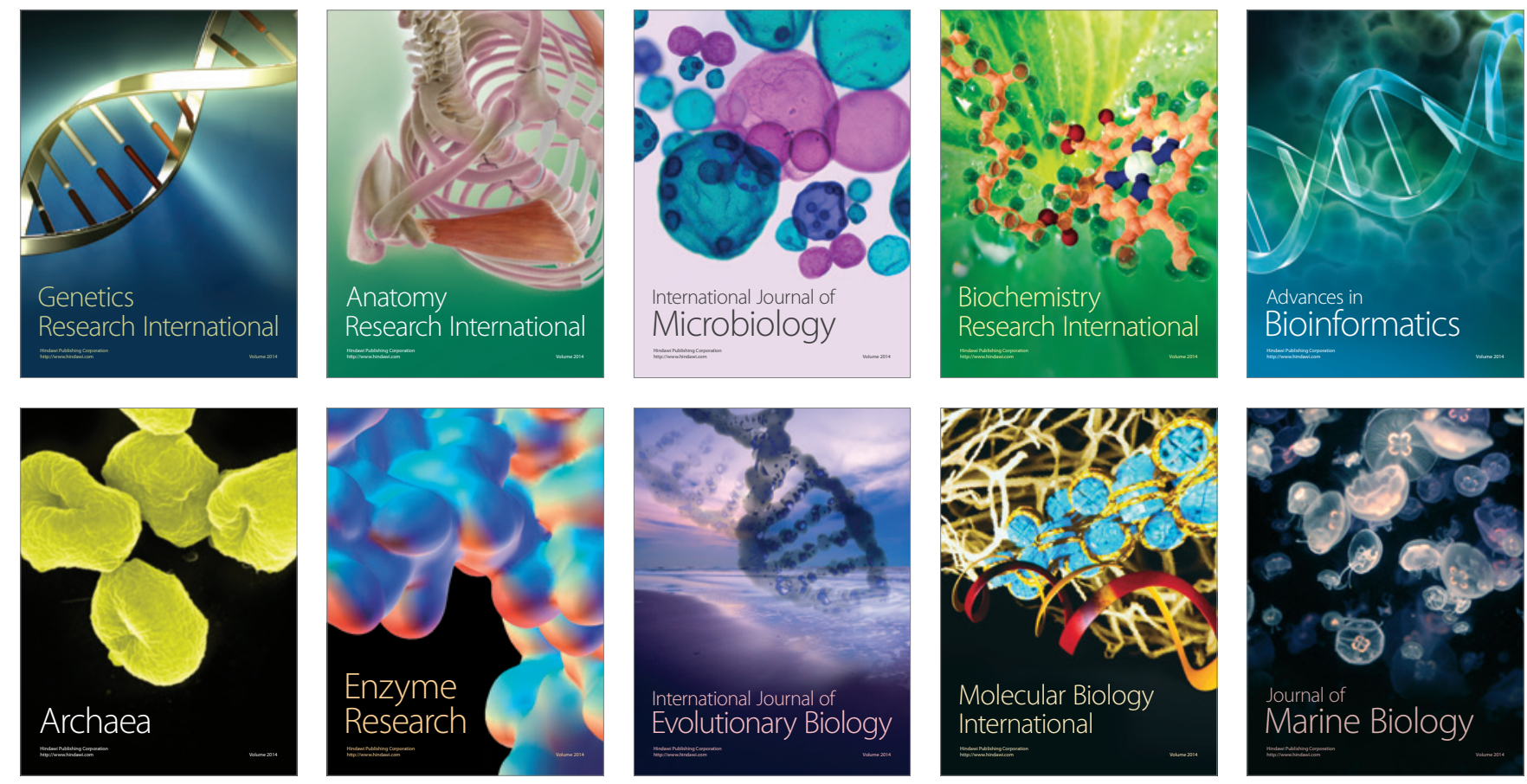